MATEC Web of Conferences 22,04014 (2015)

DOI: $10.1051 /$ matecconf/ 20152204014

(C) Owned by the authors, published by EDP Sciences, 2015

\title{
Experimental Study on Acoustic Emission Characteristics of Cemented Waste Rock Backfills with Two Different Structures during Creep Process
}

\author{
Qiantian Ma \\ Key Laboratory of the Ministry of Education for High-Efficient Mining and Safety of Metal Mines, University of \\ Science and Technology Beijing, Beijing, China \\ School of Civil and Environmental Engineering, University of Science and Technology Beijing, Beijing, China
}

\begin{abstract}
The studies on acoustic emission characteristics of cemented waste of rock backfills with two different structures during creep process were carried out by virtue of short-term creep test under different stress levels. The results show that: When two parts of the stone combinations in the test specimens are combined in a minor angle $\left(30^{\circ} \sim 60^{\circ}\right.$ ) (type I), under sustained loading without failure, acoustic emission amplitude will increase during steady creep stage with surface crack opening and propagating. When two parts of the stone combinations in the test specimens are combined in a large angle $\left(60^{\circ} \sim 90^{\circ}\right)$ (type II), under sustained loading without failure, the test specimens show two varied features. On one hand, acoustic emission amplitude will decrease significantly during steady creep stage, with surface crack opening and propagating which will mainly occur during decelerated creep stage. On the other hand, acoustic emission amplitude is rather fluctuating during sustained load stage which leads to separation and drop of parts of the test specimen. One common trait of these two types of test specimens is that, the whole decelerated creep and steady creep stages show relatively stable acoustic emission amplitude before destruction. During accelerated creep stage, acoustic emission amplitudes appear as wave type in type I test specimens with shear fracture and accretion type in type and II test specimens with tensor failure.
\end{abstract}

Keywords: cemented waste rock backfills; creep; acoustic emission; shear fracture; tensor failure

\section{INTRODUCTION}

In order to minimize the loss and improve resource recovery, artificial pillars are used to replace the roof support or hanging rock of original pillar in many rare and precious metal mines. The mine waste (tailings, stones) mixed with cementing material forming solid waste cemented filling body can reduce negative environmental impact caused by mining resource waste and save costs. At the same time, artificial pillars are the most important supporting structure for safe mining. If they are damaged in complex externally mechanical environment of underground mining, it will cause the roof caving, upper and lower strata movement, and even induces deep mining rock burst, forms a serious threat to the mining safety. So, study on solid waste of cemented filling body in complex environment of its mechanical properties and damage mechanism is an important basis for filling material selection, optimization and stability analyses. Based on these, the monitoring and prediction methods for filling body stability are important technologies to be solved.

In recent years, with the cemented filling mining method applied in many mines, solid waste of cemented filling body as a new kind of engineering material has aroused considerable concern ${ }^{[1]}$. At the same time, acoustic emission(AE) monitoring technology which can be used as a qualitative or quantitative description of Evolution of micro cracks in concrete materials under external loads ${ }^{[2 \sim 6]}$, and prediction of the catastrophe has been gradually applied to solid waste of cemented filling body stability monitoring and forecasting. The law of $\mathrm{AE}$ energy characteristics and space distribution of cemented tailings backfill during the fracturing process was studied through numerical model test by Wang Xiaojun and Feng Xiao ${ }^{[7]}$. Cemented waste rock backfills is a quasi-brittle material such as concrete, rock, its damage and $\mathrm{AE}$ are closely related. But research in this field is less.

Preparation, initiation, evolution, propagation and fracture processes of the micro ruptures in cemented waste of rock backfills happen between the stones. So, different spatical combinations of stones will have different failure modes. In this paper, the studies on $\mathrm{AE}$ characteristics of cemented waste of rock backfills with two different structures during creep process were carried out by virtue of short-term creep test under different stress levels. The results were valuable for the prediction of instability of cemented waste of rock backfills. 


\section{MATEC Web of Conferences}

\section{EXPERIMENTAL CONDITION AND} SOLUTION

\subsection{Experimental system}

The Experimental system consists of RMT-150C rock mechanics testing system and SAEU2S acoustic emission system. The maximum load of RMT-150C rock mechanics test system is $1000 \mathrm{kN}$, the piston stroke is $50 \mathrm{~mm}$ and the frame stiffness is $5 \times 106$ $\mathrm{N} \cdot \mathrm{mm}-1$. SAEU2S acoustic emission system is mult-channel acoustic signal real-time acquisition of AE transmitting system.

\subsection{Specimen preparation}

In this experiment, stone was phyllite, and tailings were classified tailings. According to particle size, stones were divided into three groups: less than $5 \mathrm{~mm}$, $5 \sim 20 \mathrm{~mm}$ and $20 \sim 50 \mathrm{~mm}$. The composition of three groups was 1:1:2. Tailings and 325\# cement silicate were used to prepare the mortar. The ratio of Cement and tailings was 1:4 and the mass concentration was $75 \%$. The specimen was a cylinder and its dimension was $\varphi 75 \times 150 \mathrm{~mm}$.

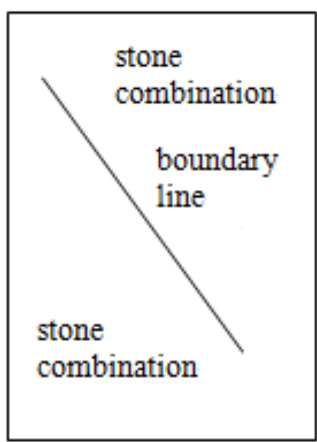

(a) Type I

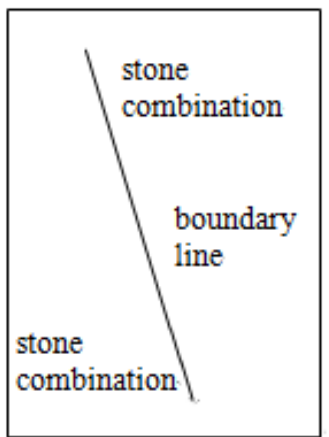

(b) Type II
Figure 1. Structure in blocky rock cemented fill.

As shown in Figure 1, different specimens were made by controlling the spatial position of large particle size of stones. In Figure 1, the stone combinations on both sides of the boundary line were combinations of large dimension stones. The boundary line was cement mortar between large dimension stones. In Figure 1(a), two parts of the stone combinations were combined in an angle of $30^{\circ} \sim 60^{\circ}$ (type I). And in Figure 1(b), two parts of the stone combinations were combined in an angle of $60^{\circ} \sim 90^{\circ}$ (type II). 17 specimens of each type were prepared. 7 of them were subjected to uniaxial compression test to obtain the average uniaxial compressive strength and other 10 specimens were subjected to short-term grade creep AE test. The specimens which were used in short-term grade creep AE experiment were numbered \#1 10 for type I and \#18 27 for type II. As shown in
Figure 2, complete stress-strain curves of two types. In Figure 2(a), the complete stress-strain curve showed that specimens of this type in the process of deformation and failure of compacting, elastic, yield and post peak stage were similar to the rock materials. And in Figure 2(b), the complete stress-strain curve showed that specimens of this type in most process of deformation and failure were dissimilar to the rock materials. After specimens reached the ultimate destruction, with the increasing of deformation, they could continue to bear partial load with quite high residual strength.

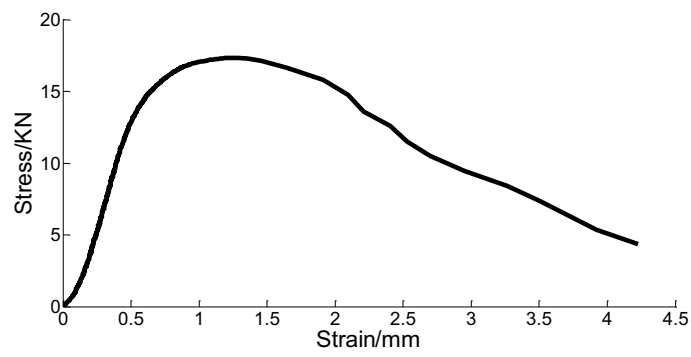

(a) Type I

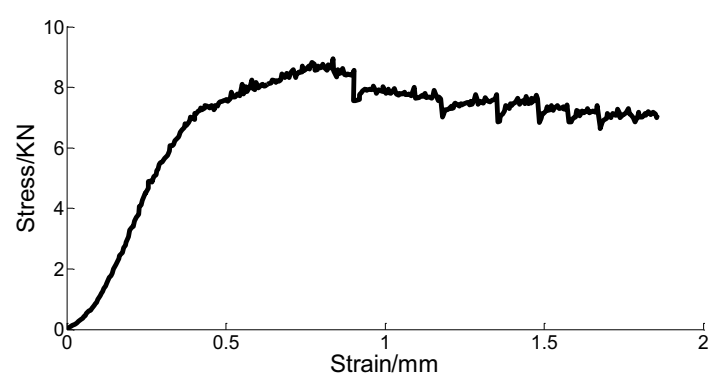

(b) Type II

Figure 2. Strain-stress curve of two types of samples.

\subsection{Experimental scheme}

Because the number of specimen was large and the $\mathrm{AE}$ data were large, short-term grade creep $\mathrm{AE}$ test was carried out in this paper. According to the average uniaxial compressive strength, five levels of stress were carried out to load on the specimens. One to five levels of stress were $40 \%, 50 \%, 60 \%, 70 \%$ and $80 \%$ of the average uniaxial compressive strength, respectively and each level was stabilized for 1 hours. The loading rate was $0.1 \mathrm{KN} / \mathrm{S}$. Acoustic emission sensor was placed in the middle part of the axis of the specimen and attached to the specimen by butter. Acoustic emission sampling length was 2048 Byte, sampling frequency was $1000 \mathrm{KHz}$ and pre amp gain was $40 \mathrm{~dB}$. Acoustic emission sensor was SR150M, and its working frequency was $20 \mathrm{kHz} \sim 400 \mathrm{KHz}$ and center frequency was $150 \mathrm{KHz}$. Since radius of stress loading probe was smaller than the radius of specimen, two larger rectangular steel plates were fixed on both ends of it. 


\section{AE CHARACTERISTICS OF TWO KINDS OF} SPECIMEN

The whole creep stage can be categorized into decelerating creep, steady creep and accelerated creep by the rate of deformation. For application of $\mathrm{AE}$ monitoring technology in materials, stability evaluation of materials is mainly based on the corresponding relationship between $\mathrm{AE}$ parameters and strain-time changing in the experiment process. Amplitude is a parameter reflecting the intensity of acoustic emission events. Based on this idea, this paper carried out monitoring of axial strain and acoustic emission in the process of short-term creep tests on the two kinds of specimen. $\mathrm{AE}$ amplitude-axial strain-time curve of every stress level can be drawn to find the AE characteristics.

Ten specimens with two kinds of cemented waste of rock backfills of different structures in the experiment showed the same acoustic emission characteristics, so only one of each kind of specimen was selected as typical for related discussion.

\subsection{AE characteristics of type I}

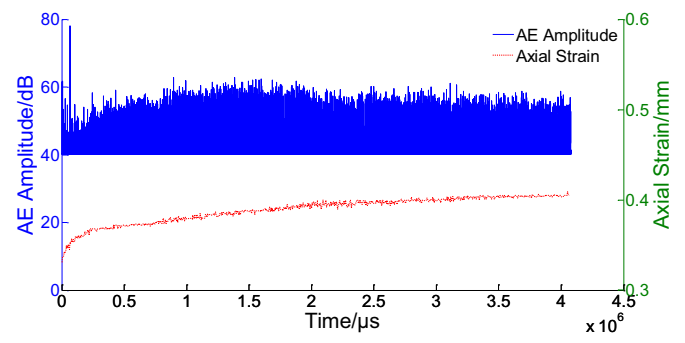

(a) The first stage of the loading

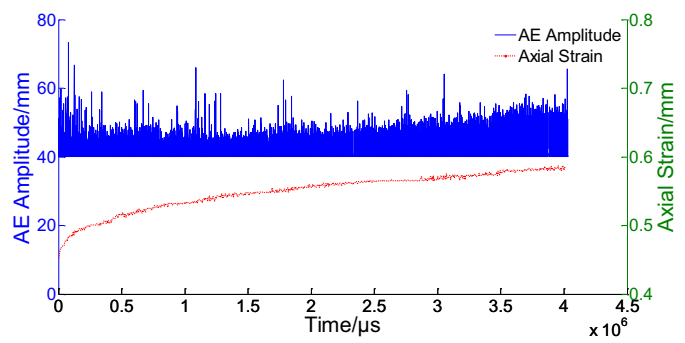

(b) The second stage of the loading

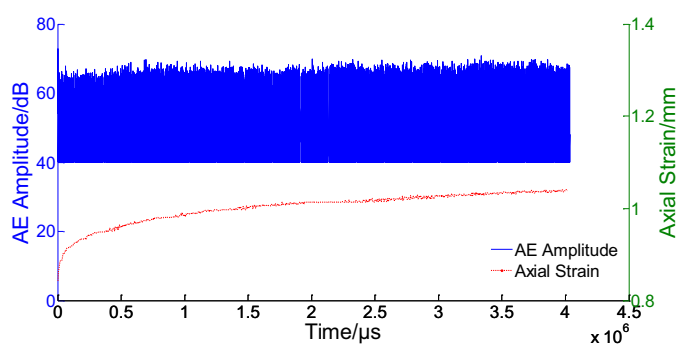

(c) The third stage of the loading

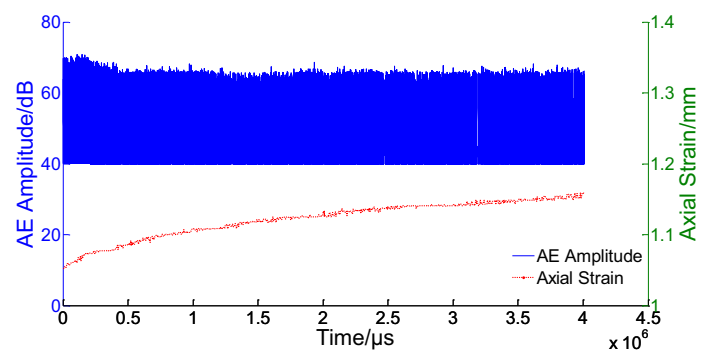

(d) The fourth stage of the loading

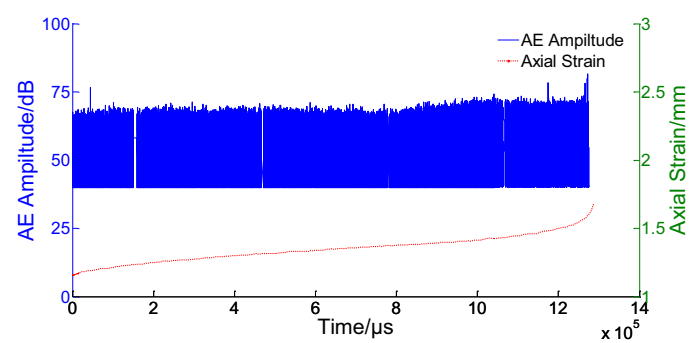

(e) The fifth stage of the loading

Figuer.3 Acoustic emission amplitude-axial train-time curve of sample 3

Specimen of \#3 was selected for related discussion of this type. Figure 3 shows the relationship among strain, $\mathrm{AE}$ amplitude and time of $3 \#$ specimen. The $\mathrm{AE}$ characteristics of type I in short-term creep test under different stress levels can be found from figure 3 and shown as follows:

1) As shown in figure $3, \mathrm{AE}$ amplitude decreased significantly in steady creep stage under the first, third and fourth sustained load. But under the second sustained load AE amplitude fluctuates strongly. Through the observation of the specimen deformation in the test, the longitudinal opening and expansion of cracks under first four sustained load could be found. And these processes occurred mainly in the decelerating creep stage. But under the second sustained load some parts were separated from the specimen and even fell from the specimen.

2) As shown in figure 3(e), AE amplitude remained stable in both decelerating creep stage and steady creep stage under the fifth sustained load. Then, AE amplitude increased slowly during steady creep transiting to accelerating creep. And the specimen broke when AE amplitude suddenly increased dramatically. Lots of crack coalescence led to breakage in accelerating creep stage.

\subsection{AE characteristics of type II}

Specimen of \#21 was selected for related discussion of this type. Figure 4 shows the relationship among strain, $\mathrm{AE}$ amplitude and time of $21 \#$ specimen. The $\mathrm{AE}$ characteristics of type II in short-term creep test under different stress levels can be found from figure 4 and shown as follows: 


\section{MATEC Web of Conferences}

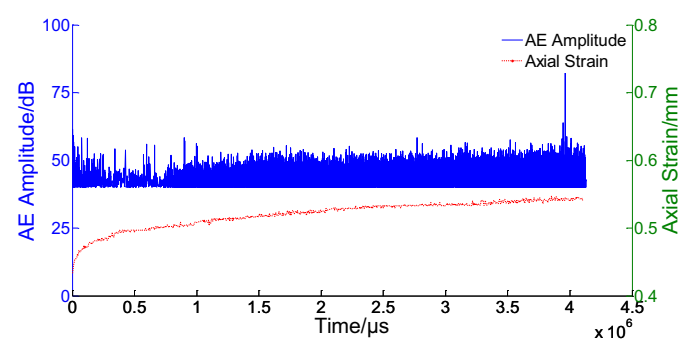

(a) The first stage of the loading

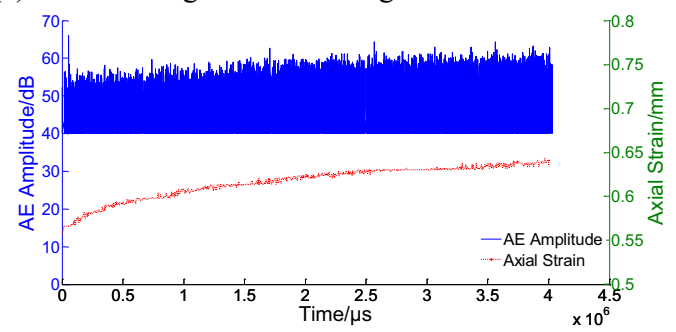

(b) The second stage of the loading

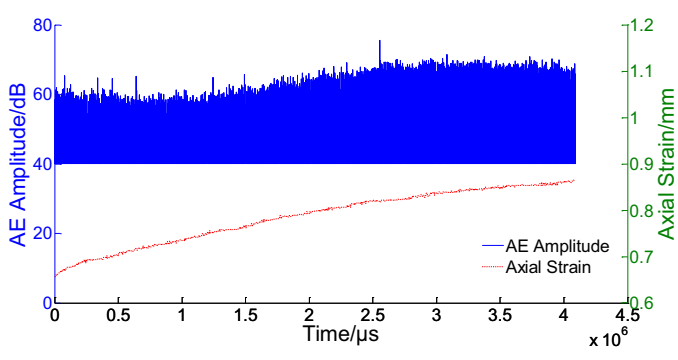

(c) The third stage of the loading

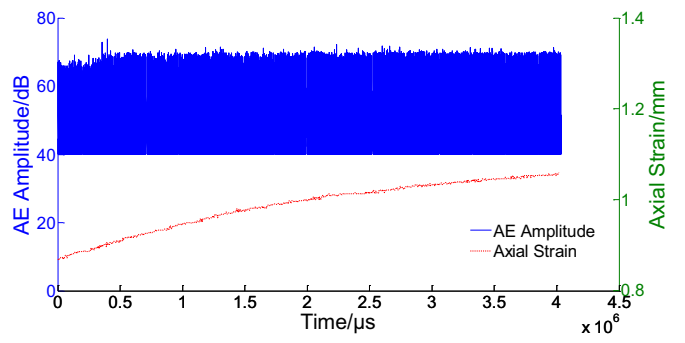

(d) The fourth stage of the loading

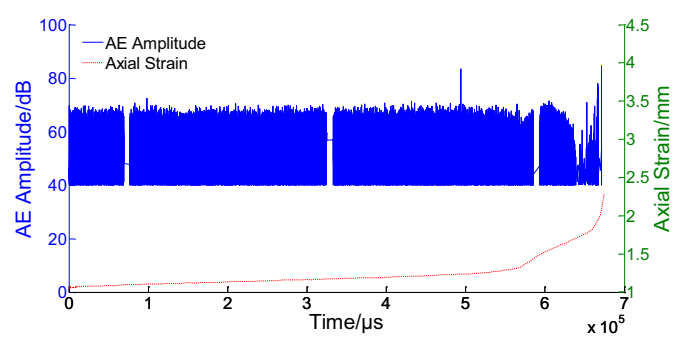

(e) The fifth stage of the loading

Figure.4 Acoustic emission amplitude-axial train-time curve of sample 21
1) As shown in figure 4, $\mathrm{AE}$ amplitude was gradually increasing during decelerating creep transiting to steady creep under the first four sustained load. The emergence and expansion of the specimen surface crack was found in the AE amplitude increasing stage under the first four sustained load by observing the deformation of specimens during the tests. It means the decelerating creep stage is actually a crack closure stage. The emergence and expansion of the crack in specimens occur during decelerating creep transiting to steady creep.

2) As shown in figure 4(e), AE amplitude remained stable in both decelerating creep stage and steady creep stage under the fifth sustained load. AE amplitude appeared fluctuation, and the fluctuation amplitude increased gradually, until the specimen broke in accelerating creep stage. The specimen surface crack was opening and expanding continuously during both decelerating creep stage and steady creep stage by observing the deformation of specimen in test. The surface longitudinal crack expanded dramatically through the whole specimen until the specimen broke under this sustained load. Due to the friction at both ends of specimen given by steel plates, the specimen could keep integrity after broken. Once the plate was taken away, the specimen would immediately collapse.

\section{CONCLUSIONS}

1) When two parts of the stone combinations in the test specimens are combined in a minor angle $\left(30^{\circ} \sim 60^{\circ}\right)$ (type I), under sustained loading without failure, acoustic emission amplitude will increase during decelerating creep transiting to steady creep with surface crack opening and propagation. This reveals the dramatic evolution of micro-cracks is happening.

2) When two parts of the stone combinations in the test specimens are combined in a large angle $\left(60^{\circ} \sim 90^{\circ}\right)$ (type II), under sustained loading without failure, the test specimens show two variation features. On one hand, acoustic emission amplitude will decrease significantly during steady creep stage, and surface crack opening and propagating will mainly occur during decelerated creep stage. This reveals the evolution of micro-cracks is happening more dramatically in decelerating creep stage. On the other hand, acoustic emission amplitude is rather fluctuating during sustained load stage which leads to separation and the drop of parts of the specimen. The separation and the drop of parts of the specimen are caused by the connection of the cracks.

3) One common trait of these two types of test samples is that, the whole decelerated creep and steady creep stages show relatively stable acoustic emission amplitude before destruction. This can be regarded as precursory characteristic of specimen failure.

4) During accelerated creep stage, acoustic emission 
amplitudes appear as wave type in specimen of type I with shear fracture, and accretion type in specimen of type II with open failure.

\section{REFERENCES}

[1] Farsangi P, Hara A. Consolidated. 1993. Rockfill design and quality control at Kidd Greek Mine. CIM Bulletin, 973: 68-74

[2] Sondergeld CH. \& Estey LH. 1981. Acoustic emission study of micro-fracturing during the cyclic loading of Westerly granite. Geophy. Res., 86: 2915-2924.

[3] OHTSU M. 1991. Simplified moment tensor analysis and unified decomposition of acoustic emission source application to in situ hydro fracturing test. Journal of Geophysical Research, 96(4): 6211-6221.

[4] Mihashi H, Nomura N. \& Niiseki S. 1991. Influence of aggregate size on fracture process zone of concrete detected with three dimensional acoustic emission technique. Cement and Concrete Research, 21(5): 737-744.

[5] Ji Hongguang, Zhang Tiansen. \& Cai Meifeng, et al. 2000. Experimental study on concrete damage by dynamic measurement of acoustic emission. Chinese Journal of Rock Mechanics and Engineering, 19(2): 165-168.

[6] Lin Feng, Li Shulin. \& Xue Yunliang. 2010 Relationship between acoustic emission parameter and mechanics parameters damage degree of concrete material. Journal of Xiamen University (Natural Science), 49(4): 526-530.

[7] Wang Xiaojun, Feng Xiao. \& Zhao Kang. 2011. Numerical simulation on acoustic emission of roof fill failure of mining drift with different cross-section. Mining $R \& D, 31(1)$ : 9-15. 